\title{
Flood-induced agricultural loss across China and impacts from climate indices
}

Qiang Zhang, Xihui Gu, Vijay P. Singh, Lin Liu, Dongdong Kong

\section{Corresponding author:}

Qiang Zhang, Ph.D. Professor, Associated editor of HSJ and editor of HP

Department of Water Resources and Environment (Department Chairman)

Sun Yat-sen University

Guangzhou 510275,

China

Tel: +86-20-84113730

Fax: +86-20-84113730

E-mail: zhangq68@ mail.sysu.edu.cn (preferred contact address) 


\section{Flood-induced agricultural loss across China and impacts from}

\section{climate indices}

Qiang Zhang ${ }^{1,2,3}$, Xihui Gu ${ }^{1,2}$, Vijay P. Singh ${ }^{4}$, Lin $_{\text {Liu }}^{3}$, Dongdong Kong ${ }^{1,2}$

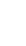

1. Department of Water Resources and Environment, Sun Yat-sen University, Guangzhou, China;

2. Key Laboratory of Water Cycle and Water Security in Southern China of Guangdong High Education Institute, Sun Yat-sen University, Guangzhou, China;

3. Guangdong Provincial Key Laboratory of Urbanization and Geo-simulation, School of Geography and Planning, Sun Yat-sen University, Guangzhou, PR China;

4. Department of Biological and Agricultural Engineering \& Zachry Department of Civil Engineering, Texas A\&M University, College Station, Texas, USA; 15

(6)

ABSTRACT: Province-wide data on flood-destroyed and flood-affected crop areas across China covering a period of 1960-2013 were analyzed in this study for investigating their relations with climate indices, such as ENSO, NAO, IOD, PDO and AMO. Results indicated that: (1) agricultural flooding in northeast and south China tended to enhance under the influence of warm PDO and warm IOD events of the previous years. However, agricultural flooding in southwest China tended to decrease as a result of warm ENSO events of the previous years. Agricultural floods 
1 in coastal regions of southeast China were influenced by more than one climate

2 index; (2) Agricultural floods of different time scales were subject to different

3 degrees of correlations with climate indices. Remarkably, climate indices that were

$4 \quad$ significantly correlated with agricultural floods were usually temporally enhancing.

5 Relations between ENSO and agricultural floods across China were statistically

6 strong with good persistency. Thus, ENSO can be taken as a suitable predictor for

7 flood-affected and flood-destroyed crop areas across China. However, AMO cannot

8 be taken as the predictor for flood-affected and flood-destroyed crop areas in China;

9 (3) The combined influence of climate indices on flood-affected and flood-destroyed crop areas across China did not have a firm spatiotemporal pattern. However,

11 specific groups of climate indices can have definitive impacts on flood-affected and

Key words: Climate indices; Flood hazards; Agricultural loss; Stability analysis

\section{Introduction}

As a result of emission of greenhouse gas, global warming is alleged to be accelerating the global hydrological cycle (Allen and Ingram, 2002; Alan et al., 2003). This acceleration is altering spatiotemporal patterns of precipitation and hence increased occurrences of extremes (Easterling et al., 2000; Dore, 2005) and in 
turn increased occurrences of floods and droughts in many regions of the world (e.g. Easterling et al., 2000; Mirza, 2002). There is a general belief that extreme flood events will occur more frequently due to the change in climate, particularly in the backdrop of warming climate and increasing land use (Reynard et al., 2001; Posthumu et al., 2008; Das et al., 2013).

In recent years, climate change and impacts thereof on human society, particularly on agriculture and food security, have received an unprecedented importance (e.g., Schmidhuber and Tubiello, 2007; MacDonald, 2010) because of the concern for the role of availability, accessibility and security of food, energy and water in the stability and sustainability of society. Chau et al. (2013) analyzed impacts of floods on agriculture in Vietnam using GIS, and results indicated that the 1:10, 1:20 and 1:100 year floods led, respectively, to $27 \%, 31 \%$, and $33 \%$ of the arable land inundation. Since the exact loss of agricultural production will depend upon a number of factors, including crop variety, stage of plant development, length of flooding period and level of inundation, Posthumu et al. (2008) indicated that recent changes in agricultural and flood defense policies create new opportunities for involving rural land use, in particular agriculture, in flood risk management. Xu et al. (2013) also indicated that flood catastrophe risk assessment is the key step to the steady development of agriculture in the backdrop of climate change. Meanwhile, it is an important scientific issue that needs to be addressed for agricultural risk assessment.

1 China has the largest population in the world and its arable land accounts for $7 \%$ of the world arable land, and meets the food demand of $22 \%$ of the global population 
1 (Piao et al., 2010). It is expected that in the next twenty years, 30\%-50\% more food

2 would be required to support the fast growing population (Zhang et al., 2013).

3 However, frequent floods and droughts greatly limit the development of agriculture in

4 China. Xu et al. (2013) indicated that the impact of flood catastrophes on grain

5 production in China was quite serious, and high or very high risk of flood catastrophes

6 concentrated in central and eastern regions. For a majority of major grain producing

7 provinces, the probability of $10 \%$ reduction in grain output is more than $90 \%$, given

8 the one-hundred-year flood disaster (Xu et al., 2013). Climate change adds a

9 significant degree of uncertainty to projections of agricultural output in China. Zhang

et al. (2013) identified different regional responses of precipitation extremes to

11 increasing temperature across China. Under the influence of increasing temperature, precipitation is intensifying in southeastern China. The responses of changes in weak precipitation extremes to climate warming are comparatively complicated and diverse.

Nevertheless it can be confirmed that increasing temperature tends to trigger the

15 intensification of precipitation (Zhang et al., 2013a). Alterations of precipitation regime greatly increase the risks of floods and droughts across China (Zhang et al., 2011). Furthermore, future decades are expected to witness higher risks of floods. Li et al. (2015) indicated that during 2021-2050 and 2071-2100, there would be less 19 co-occurrence of consecutive wet and dry days, and more joint extreme heavy precipitation events, implying less risk of co-occurrence of floods and droughts in the same year but higher risk of floods in China. 

and Depetris, 2010; Räsänen and Kummu, 2013; Zaroug et al., 2014). Bouwer et al.

2 (2008) analyzed relations between annual mean, maximum streamflow and the North

3 Atlantic Oscillation (NAO), the Arctic Oscillation (AO), the frequency of west

4 circulation (FWC) and south sea level pressure difference (SLPD), indicating that 5 the annual maximum streamflow was subject to larger sensitivity to changes of 6 climate indices. Delgado et al. (Delgado et al., 2012) developed models using 7 discrete wavelet transform (DWT) to analyze the impacts of ENSO and PDO on 8 flood variations of the Mekong River, suggesting that the sea surface temperature of 9 the Pacific and monsoon activities can be taken as the predictors for flood changes in the lower Mekong River basin. Impacts of ENSO, NAO, IOD, PDO and AMO on East Asian monsoon have also been well studied (Wang et al., 2009; Zhang et al., 2014; Xiao et al., 2015), particularly on precipitation changes in China (e.g. Zhang et al., 2013b; Ouyang et al., 2014). However, studies have mainly focused on the impacts of ENSO and related climate indices, such as the North Atlantic Oscillation available pertaining to the impacts of climate indices on agricultural flood hazards. It should be noted here that the understanding of impacts of floods on agriculture is important for management of agricultural activities and food security. The objectives of this study therefore are: (1) to investigate influence of ENSO, NAO, IOD (Indian Ocean Dipole), PDO (Pacific Decadal Oscillation) and AMO (Atlantic Multidecadal 
1 and (2) to analyze possible mechanisms behind the influence of ENSO, NAO, IOD,

2 PDO and AMO on agricultural floods across China. This study can help understand

3 flood-destroyed and flood-affected agricultural crop areas and impacts of climate

4 indices on agriculture in China.

\section{Data}

Data on flood-destroyed and flood-affected crop areas from 26 provinces

8 covering a period of 1960-2013 were collected from the Agriculture Department of

9 China via http://202.127.42.157/moazzys/zaiqing.aspx and were analyzed in this study (Fig. 1) (Zhang et al., 2012). Missing data, if any, during 1967-1969 were

11 handled using the long-term annual mean values. The flood-destroyed and 12 flood-affected crop areas were defined, respectively, as crop areas with agricultural 13 loss exceeding $30 \%$ and $10 \%$ of agricultural production. These thresholds are ascertained by the ministry of agriculture of the People's Republic of China at 15 http://202.127.42.157/moazzys/zaiqing.aspx, which are used to distinguish the loss degree caused by flood disasters to agriculture. This concept of flood-destroyed and flood-affected crop areas can well mirror the negative influence of flood hazards on agricultural production. Fig. 1 indicates that flood-induced agricultural loss is

19 observed mainly in the coastal regions and south, southeast and central parts of China with high flood-destroyed crop area/flood-affected crop area percentage above 45\%. ENSO in this study refers to the SST in the Niño 3.4 zone $\left(5^{\circ} \mathrm{N}-5^{\circ} \mathrm{S}\right.$, 
1 NOAA (Climate Prediction Center of National Oceanic and Atmospheric

2 Administration)

at

3 http://www.cpc.ncep.noaa.gov/products/analysismonitoring/ensostuff/ensoyears.sht

$4 \mathrm{ml}$. NAO is defined as a meridional dipole in atmospheric pressure with centers of

5 action near the Azores and Iceland. A high NAO index is associated with stronger

6 than average westerlies in the North Atlantic mid-latitudes, while the opposite is true

7 for negative values of the index (Moore et al., 2013). The NAO index is calculated

8 by applying rotated principal component analysis, and here the values for the NAO

9 index are taken from the Climate Prediction Center of NOAA (http://www. cpc.ncep.noaa.gov/products/precip/CWlink/pna/nao.shtml). IOD is a kind of

11 ocean-atmosphere coupling phenomenon and is quantified by Dipole Mode Index

12 (DMI), being defined as the temperature anomaly between the western equatorial

13 Indian Ocean and the southeastern equatorial Indian Ocean. The IOD data covering the period of 1950-2013 were obtained from Japan Agency for Marine-Earth Science and Technology at http://www.jamstec.go.jp/frsgc/research/d1/iod/iod/dipole_mode_ index.html. PDO is the SST anomalies in the Pacific north to $20^{\circ} \mathrm{N}$. The PDO data covering the period of 1950-2013 were extracted from NOAA at http://www.esrl. noaa.gov/psd/data/correlation/pdo.data. The Atlantic Multidecadal Oscillation (AMO)

19 is a mode of variability occurring in the North Atlantic Ocean that has its principal expression in the sea surface temperature (SST) field. The AMO data were obtained from NOAA at http://www.esrl.noaa.gov/psd/data/timeseries/AMO/. The values of 
1 are monthly atmospheric and ocean time series. Monthly atmospheric and ocean

2 time series (climate index) were aggregate by averaged over the year, which is refer

3 to Villarini et al., 2012 and Xiao et al., 2014. The annual variations with warm and

4 cold episodes of ENSO, NAO, IOD, PDO and AMO are displayed in Fig. 2.

\section{Methodology}

\subsection{Spatial decomposition of flood-affected and flood-destroyed crop areas}

The flood-destroyed and flood-affected crop area data exhibit nonlinear, inter-correlative and multi-dimensional features. To reduce the dimension and also to avoid inter-correlation, the Rotated Empirical Orthogonal Functions (REOF) method (Hannachi et al., 2007) was used to analyze the spatial patterns and also the principle components (PC) of flood-destroyed and flood-affected crop areas across China. The REOF technique was introduced in details in Hannachi et al. (2007) and was used in the decomposition of seasonal precipitation changes into spatial patterns and associated temporal patterns (Xiao et al., 2015). Here, further introduction of the REOF technique is not provided to avoid redundancy.

3.2 Correlation between climate indices and flood-destroyed and flood-affected crop areas

Correlation between climate indices and flood-destroyed and flood-affected crop areas was done using the Pearson correlation analysis technique. It should be noted here that climate indices influence flood-destroyed and flood-affected crop areas in 
1 the same year or in subsequent years. Thus, correlations between climate indices and

2 flood-destroyed and flood-affected crop areas were done with 0 - and 1-year time lag.

3 Correlation analysis was done with 1951 as the starting time point and 5 year as the

4 time interval.

$6 \quad 3.3$ Difference between flood-destroyed and flood-affected crop areas under the $7 \quad$ influence of warm and cold episodes of climate indices

8 To understand the influence of warm and cold episodes of climate indices, 9 changing properties of flood-destroyed and flood-affected crop areas were analyzed 10 during the warm and cold episodes of climate indices. In so doing, the

11 flood-destroyed and flood-affected crop area series corresponding to warm and cold 12 episodes, respectively, of the ENSO, NAO, IOD, PDO and AMO events were 13 extracted and analyzed using the Student $t$ test technique. The significance of the relations between flood-destroyed and flood-affected crop areas and related cold and 15 warm episodes of climate indices was tested at $95 \%$ confidence level. Besides, the influence of one or more climate indices on the changes in flood-destroyed and 17 flood-affected crop areas was analyzed. Specifically, the time intervals characterized by: (1) the warm and cold episodes of PDO and AMO; and (2) the warm and cold 19 episodes of ENSO, NAO and IOD, were extracted and the flood-destroyed and flood-affected crop areas during these time intervals were analyzed and relations were determined using the Student $t$ test. The significance of correlation was tested at $95 \%$ confidence level. 


\section{Results and discussion}

34 4.1 Influence of climate indices on spatial and temporal patterns of flood-destroyed and flood-affected crop areas

It can be seen from Fig. 3 that 6 modes can be chosen for further analysis with the total explained variance of $70 \%$ and $72 \%$, respectively, for the flood-affected crop area and the flood-destroyed crop area. After the seventh rank, the changes of eigenvalue are flattened and no evident changes can be identified. After deciding the number of modes, correlation relations between climate indices and temporal modes were analyzed (Fig. 4). The climate index with a suffix of ' 0 ' and ' 1 ' denote the climate index with 0- and 1-year ahead of the occurrence of flood-affected crop areas or flood-destroyed crop areas, respectively (Fig. 4). It can be observed from Fig. 4 that significant negative correlations can be observed between IOD and PC1 of the flood-affected crop area of the next year; and significant positive correlations between ENSO and PC1 of the flood-affected area of the next year. NAO also has significant positive correlation with PC2 of the flood-affected crop area of the next year. Thus, IOD, ENSO and NAO usually caused flood-induced agriculture losses in the next year. However, significant positive correlations can be identified between PDO and PC4 of the flood-affected crop area of the same year and the next year. Significant negative correlation can be observed between ENSO and PC4 of the flood-affected crop area of the next year. AMO and ENSO have significant negative correlations with PC4 of the flood-affected crop area in the same year and the next 
1 year and PDO has significant negative correlation with PC5 of the flood-affected

2 crop area in the next year. A different picture emerges for correlations between

3 climate indices and the flood-destroyed crop area (the lower panel of Fig. 4). PDO

4 exhibits a significant negative correlation PC2 of the flood-destroyed crop area, and

$5 \quad$ PDO and ENSO have significant negative and positive correlations with PC4 and

6 PC5, respectively, of the flood-destroyed crop area. Besides, significant negative

7 correlations can be found between PDO and PC4 of the flood-destroyed crop area of

8 the same year. The PC6 variations are heavily influenced by more than one climate

9 index. AMO has a significant positive correlation with PC6 of the flood-destroyed crop area of the same year, and PDO and IOD have significant positive correlations

11 with PC6 of the flood-destroyed crop area of the next year. However, ENSO has a significant negative correlation with PC6 of the flood-destroyed crop area of the next year.

Figs. 4 and 5 combine to show the influence of climate indices considered in this study on the flood-induced agricultural loss across China. It can be observed from Figs. 4 and 5 that warm phases of IOD (ENSO) can lead to increased (decreased) flood-affected crop areas in northwest and southwest China (EOF1 in Fig. 5). Flood-affected crop areas in northeast and east China increased during the warm phase of NAO (EOF2 in Fig. 5). The flood-affected crop area increased in northwest and central China under the influence of warm phase of PDO during the same year and one-year earlier. However, warm phases of ENSO can trigger decreased flood-affected crop area in northwest and central China (EOF4 in Fig. 5). In 
northeast China and also in the coastal regions of south China, the flood-affected crop area had an increasing tendency due to the warm phase of PDO of the previous year (EOF5 in Fig. 5). Changes in the flood-affected crop area in the provinces in east and south China are influenced by more than one climate index, e.g. warm phase of PDO of the same year and the previous year and warm phase of NAO in the previous year tended to cause an increase in the flood-affected crop areas; and the warm phase of AMO of the previous year and also the warm phase of ENSO of the same year tended to trigger a decrease in the flood-affected crop area.

Spatial patterns of flood-destroyed crop areas due to the influence of different climate indices show different pictures when compared to those of the flood-affected crop areas (Figs. 4, 5 and 6). Figs. 4 and 6 indicate an increase in the flood-affected crop area during the warm phase of PDO of the previous year in northeast China and also in the coastal regions of south China (EOF2 in Fig. 6). Warm phases of PDO of the very year and the previous year and cold phase of ENSO of the previous year tended to trigger an increase in the flood-destroyed crop areas in central China and also in the coastal provinces of east China (EOF4 in Fig. 6). Under the influence of warm phase of PDO and cold phase of ENSO during the previous year, an increase in the flood-destroyed crop areas was observed in northeast and central China and a decrease in the flood-destroyed crop area in the eastern parts of central China (EOF5 in Fig. 6). Changes in the flood-destroyed crop area in east China and also in the coastal regions of south China are influenced by more than one climate index: an increase in the flood-destroyed crop area can be observed under the influence of 
warm phase of AMO of the same year and warm phases of PDO and IOD of the previous years. However, the warm phase of ENSO of the previous year tends to cause a decrease in the flood-destroyed crop areas (EOF6 in Fig. 6). Changes in flood-affected and flood-destroyed crop areas should be attributed to different magnitudes of flood events under the influence of different climate indices, and also to topographical features of different regions. Provinces in the central and coastal regions of east and south China are mostly low-lying areas and are sensitive to flood inundation. Besides, rainstorms in central and south China are becoming frequent (e.g. Zhang et al., 2011) and they have the potential to trigger more frequent and serious floods. These results provide a scientific reference for the management of agricultural activities based on occurrences of different climate indices.

4.2 Constancy of the influence of climate indices on flood-induced crop area changes Temporal variations of ENSO, NAO, IOD, PDO and AMO are evident for various time scales from decades to hundreds of years. Besides, spatial ranges under these climate indices are also wide. Spatial and temporal patterns of the influence of above-mentioned climate indices on flood-induced agricultural losses are shifting. Correlations between temporal modes of REOF and flood-affected and flood-destroyed crop areas were analyzed with a moving time window of 5 years. In so doing, the moving correlation results shed light on the constancy of influences of climate indices on flood-affected and flood-destroyed crop areas across China.

Fig. 7 demonstrates moving correlation coefficients between climate indices and flood-affected crop areas of the next year. The climate indices with a year ahead of 
1 the occurrence of flood-affected crop areas are denoted as ENSO_1, NAO_1, IOD_1,

2 PDO_1, and AMO_1. Fig. 7 indicates consistent positive and negative correlations

3 between ENSO_1, PC1 and PC4, and particularly the correlation between ENSO_1

4 and $\mathrm{PC} 1$ is persistently steady. Meanwhile, increasingly stronger correlation can be

5 detected between ENSO_1 and PC4. As for NAO_1, weakening correlations can be

6 observed between NAO_1 and PC1, relatively steady correlation relations between

7 PC2 and NAO_1, and increasingly stronger correlation between NAO_1 and PC6.

8 The influence of IOD on the flood-affected and flood-damaged crop areas is

9 different when compared to ENSO, and NAO_1. Enhancing correlations can be 10 identified between IOD_1 and PC1 and weakening correlations between IOD_1 and 11 PC2-PC6; while weakening correlations can be observed between IOD_1 and PC1, 12 and PC2 and PC6. Negative correlations between IOD_1 and PC3 before 1971 shift 13 to positive correlations after 1971 and constantly positive and negative correlation are kept between IOD_1, PC4 and PC5. Correlations between AMO_1 and all the 15 PCs of the flood-affected crop areas are largely unsteady and positive correlations 16 shift to negative correlations between AMO_1 and PC1, PC3, PC4 and PC6, 17 respectively. and climate indices of the same year, denoted as ENSO_0, NAO_0, IOD_0, PDO_0 and AMO_0, are illustrated in Fig. 8. When compared to correlations between flood-affected crop areas and climate indices with one year ahead, correlations between flood-affected crop areas and climate indices of the same year are weaker. It 
can be depicted from Fig. 8 that the influence of ENSO_0 on PC1 is weakening and

2 the influence of ENSO_0 on PC6 is enhancing. Correlations between NAO_0 and

3 PC1 shift from positive to positive and negative correlations between NAO_0 and

4 PC3 are weakening, and correlations between NAO_0 and PC6 are enhancing.

5 Correlations between other climate indices, such as IOD_0, PDO_0, AMO_0, and

$6 \quad$ PCs of flood-affected crop areas are weak or unsteady and are characterized by shifts

7 from positive/negative to negative/positive correlations. No confirmative or fixed

8 correlation patterns can be detected. Thus, the occurrences of ENSO, NAO, IOD,

9 AMO and NAO usually have evident influences on the occurrences of floods and hence the flood-affected crop areas in subsequent years.

Figs. 9 and 10 demonstrate correlations between climate indices and

REOF-based PCs of flood-destroyed crop areas. Fig. 9 shows strong correlations between ENSO and PC3, PC4 of the subsequent years and the correlations are steady. Besides, enhancing correlations are observed between ENSO and PC3. However, weak correlations are detected between NAO, IOD and PCs of the flood-destroyed crop areas across China and these correlations are relatively unsteady. PDO and AMO have strong influences on the flood-destroyed crop areas of the subsequent years. Specifically, significant negative correlations are observed between PDO and PC2, PC4 and PC5 of the subsequent years and correlations between PDO, AMO and PC2, PC4 are enhancing. However, correlations between AMO and PC1, PC5 shift from positive correlations to negative correlations. Comparatively, weaker and relatively unsteady correlation relations can be observed between changes in climate 
1 indices and PCs of flood-damaged crop areas of the same year. Relatively weak

2 negative, positive and negative correlations are found between ENSO_0 and PC3,

3 PC4 and PC6, respectively. Shifts from weak negative correlations to weak positive

4 correlations are found between NAO_0 and PC1 and PC5. Besides, weak

5 correlations and positive correlations vs. negative correlations shifts are found

6 between PDO_0, AMO_0 and REOF-based PCs of food-damaged crop areas.

7 In summary, Figs. 4, 7-10 indicate strong correlations between REOF-based PCs

8 of flood-affected crop areas and climate indices except AMO, and correlations tend to

9 be enhancing, e.g., correlations between IOD_1, ENSO_1 and PC1, NAO_1 and PC2, PDO_0, PDO_1, ENSO_1 and PC4, PDO_1 and PC5 in Figs. 4, 7-8. These results help provide insights into the prediction of flood-affected crop areas. Similar spatial and temporal patterns of correlations between flood-destroyed crop areas and climate indices are found when compared to those between flood-affected crop areas and climate indices, e.g. correlations between PDO_1 and PC2, PDO_1, ENSO_1 and PC4 (Figs. 4, 9-10). However, correlations between flood-destroyed and climate indices are relatively weaker and unsteady in comparison with those between flood-affected crop areas and climate indices (Figs. 7-10), which should be attributed to alleviate the flood-induced influence on agriculture in China by mitigation of flood hazard (Zhang et al., 2012, 2015). Enhanced mitigation of flood hazards greatly reduces flood-destroyed crop areas in China. Consistency and stability of the influences that ENSO, NAO and IOD have on flood-affected crop areas are higher than those PDO and AMO have. Furthermore, the influence of ENSO on flood-affected and flood-destroyed crop areas is more evident than other climate indices considered in this study. 
14.3 Influence of cold and warm phases of climate indices on flood-affected and

2 flood-destroyed crop areas across China

3 Differences in changes in flood-affected and flood destroyed area under the

4 influence of cold and warm episodes of climate indices were analyzed. The

5 differences were defined as: flood-affected crop areas during cold episodes-

6 flood-affected crop areas during warm episodes)/flood-affected crop areas during

7 warm episodes (Fig. 11); flood-destroyed crop areas during cold episodes-

8 flood-destroyed crop areas during warm episodes)/flood-destroyed crop areas during

9 warm episodes (Fig. 12). Besides, combined influences of all the climate indices

10 considered in this study on flood-affected and flood-destroyed crop areas were

11 investigated. The significance of analysis was tested using the Student t test

12 technique at $95 \%$ confidence level.

Fig. 11 illustrates the spatial distribution of differences in flood-affected crop areas due to warm and cold episodes of climate indices, i.e. ENSO, NAO, IOD, PDO and AMO. It can observed from Fig. 11 that more flood-affected crop areas are detected in 15 provinces of China under the influence of cold episodes of ENSO when compared to those under warm episodes of ENSO. Specifically, increasing magnitude of flood-affected crop areas due to cold episodes of ENSO is higher in

19 Shanxi, Shannxi, Hubei and Jiangxi provinces, reaching 70.7\%, 76.9\%, 76.5\% and $75.4 \%$, respectively. Locations of these provinces can be seen in Fig. 1. However, a decrease in flood-affected crop areas is identified under the influence of cold ENSO

22 episodes in the coastal provinces except Zhejiang province, and the largest 
decreasing magnitude of $30.8 \%$ of flood-affected crop areas can be found in Jilin province, and the decreasing magnitude of flood-affected areas of other coastal provinces ranges lower than $20 \%$. The difference in flood-affected crop areas due to cold and warm ENSO episodes is not statistically significant at $95 \%$ confidence level (Fig. 7a). Flood-affected crop areas decrease significantly under the influence of cold NAO episodes in all provinces, except Hebei, Shanxi and Shandong provinces (Fig. 7b). Statistically significant difference between flood-affected crop areas during cold NAO episodes and during warm NAO episodes is detected in 14 provinces and these provinces are concentrated in central and southwest China. Specifically, the largest decreasing magnitude of flood-affected crop areas due to cold NAO episodes is observed in Yunnan, Sichuan, Guizhou and Guangxi provinces, and the decreasing magnitude reaches $67.9 \%, 68.6 \%, 70.2 \%$ and $64.3 \%$, respectively. Note also that flood-affected crop areas due to cold NAO episodes are evidently larger than those due to warm NAO episodes, being $361 \%$ and $70.6 \%$, respectively (Fig. 11b). Comparatively, the difference in flood-affected crop areas under warm and cold IOD episodes is smaller than those under ENSO, NAO, PDO and AMO. Increased flood-affected crop areas under cold IOD episode can be found in 15 provinces and these provinces are mainly in eastern China and also Sichuan and Gansu provinces in central China. Cold IOD episodes trigger a decrease in flood-affected crop areas in western and southern China (Fig. 11c). The largest difference between flood-affected crop areas during cold NAO episodes and those during warm NAO episodes is observed mainly in Hebei and Ningxia, being $+57.8 \%$ and $-67.1 \%$, 
respectively (Fig. 11c). Similar spatial patterns of flood-affected crop areas can be

2 found for PDO when compared to NAO so no detailed discussion will be presented

3 here (Fig. 11d). As for AMO, flood-affected crop areas during cold AMO episodes

4 are larger than those during warm AMO episodes and can be observed mainly in

5 northeastern China, in the coastal regions of south China and also in central China.

6 The difference between flood-affected crop areas during cold and warm AMO

7 episodes, respectively, is the largest in Heilongjiang and Hebei provinces, being

$8+87.0 \%$ and $-62.6 \%$, respectively (Fig. 11e).

9 Changes in flood-destroyed crop areas due to warm and cold climate episodes, i.e., ENSO, NAO, IOD, PDO and AMO, are presented in Fig. 12. In comparison

11 with Fig. 11, the difference in flood-destroyed crop areas due to cold and warm 12 climate episodes and spatial patterns thereof are similar to flood-affected crop areas 13 (Figs. 11-12). Fig. 12a shows that flood-destroyed crop areas increased during cold ENSO events when compared to warm ENSO events in 17 provinces and these 15 provinces are found mainly in central, western and southwestern China. Specifically, the increasing magnitude of flood-destroyed crop areas is the largest in Jiangxi, Hebei and Shannxi provinces, reaching 70.7\%, 92.9\% and 90.7\%, respectively (Fig. 12a). When it comes to NAO, provinces dominated by increase or decrease of

19 flood-destroyed crop areas due to cold or warm NAO episodes are similar in spatial distributions with different increasing or decreasing magnitudes. Particularly, the flood-destroyed crop areas due to warm NAO episodes are similar to those due to cold NAO events (Fig. 12b). Besides, when compared to flood-destroyed crop areas 
1 due to warm IOD events, more evident increase can be found in flood-destroyed

2 crop areas under cold IOD events in all the coastal provinces and the nearby

3 provinces, however the opposite is found in western China. The increasing

4 magnitude is evidently larger than the decreasing magnitude of flood-destroyed crop

5 areas due to cold IOD regimes, being $+93.6 \%$ and $-44.6 \%$, respectively (Fig. 12c).

6 The spatial distribution and related changing magnitudes of flood-destroyed crop

7 areas due to warm or cold PDO and AMO events are similar to those due to IOD

8 (Figs. 11d, 11e; Figs. 12d, 12e). Influences of individual climate indices in terms of

9 warm and/or cold episodes on changes of flood-destroyed crop areas are distinctly

10 different (Figs. 11, 12), implying that crop areas or agriculture in a region can be

11 impacted by more than one climate index. Hence, investigation of combined

12 influences of various climate indices will be considerable value. Thus, comparison is

13 done to anatomize differentiations in changes of flood-destroyed and flood-affected

14 crop areas due to nexus of warm and cold episodes of ENSO, NAO, IOD and PDO,

15 AMO, such as cold ENSO event/cold PDO event $\sim$ cold ENSO event/warm PDO event (Figs. 13-14).

Fig. 13 illustrates changes in flood-affected crop areas under the combined influence of ENSO, NAO, IOD and PDO, AMO across China. It can be observed from Fig. 13 that a decrease in flood-affected crop areas is detected during cold PDO events in central, northeast and western China. However, no confirmed impacts can be found from cold or warm ENSO events. Besides, a decrease of flood-affected crop areas can be identified during cold NAO and cold PDO regimes in most provinces of China (Fig. 11b, 11d), however, an increase in flood-affected crop areas can be 
1 observed during cold NAO and PDO events in northeast, northwest and south China, and it is particularly true for northeast China where an increase in flood-affected crop areas is significant at $95 \%$ confidence level. The nexus of warm NAO events and cold PDO events causes an evident decrease of flood-affected crop areas in east and northeast China. Moreover, when compared to flood-affected crop areas under the combined influence of cold PDO and warm IOD events, a decrease of crop areas can be expected under the combined influence of warm PDO and warm IOD events in south and northeast China. Comparatively, cold IOD and cold PDO events can combine to trigger a decrease in flood-affected crop areas in most provinces of China, except Hebei, Shandong and Liaoning provinces, and a significant decrease in crop areas can be detected in Gansu, Sichuan, Yunnan, Guizhou, Hunan, Jiangxi and Zhejiang provinces. Nevertheless, a substantial increase of flood-affected crop areas can be found in all the coastal provinces during cold AMO and cold ENSO events and the opposite results can be obtained for the remaining provinces. An increase in flood-affected crop areas in almost all provinces except Hebei and Shandong can be detected during cold AMO but warm ENSO events. The flood-affected crop areas are decreasing in northeast China during cold AMO and cold NAO regimes. Besides, cold AMO and warm NAO combine to cause an increase in flood-affected crop areas in northeast north and east China. Warm AMO events, whether cold or warm IOD events, can cause an increase in flood-affected crop areas in most of the provinces and mainly in south and northeast China (Fig. 13).

Changes in flood-affected crop areas under the combined influence of ENSO, NAO, IOD and PDO, AMO across China are demonstrated in Fig. 14. Figs. 13 and 14 indicate similar spatial patterns of flood-affected and flood-destroyed crop areas under the combined influence of climate indices. It can be seen from Fig. 14 that an evident 
1 increase in flood-destroyed crop areas is detected in Shandong, Anhui, Jiangxi and

2 Fujian provinces during cold PDO and NAO events. Besides, Fig. 14 shows more

3 evident impacts of AMO, ENSO, NAO and IOD on flood-destroyed crop areas when

4 compared to the impacts of these climate indices on flood-affected crop areas. Besides,

5 cold AMO and cold ENSO regimes tend to trigger an apparent decrease of

6 flood-destroyed crop areas in southwest China. Furthermore, an evident decrease in

7 flood-destroyed crop areas can be depicted during cold AMO and cold NAO events in

8 the coastal provinces in east China, implying that higher frequency of floods can be

9 expected during warm AMO and cold NAO periods in the coastal provinces. The

10 influence of single climate index on flood-affected and flood-destroyed crop areas is

11 greatly altered by the influence of other climate indices or the combined influence of

12 more than one climate index (Figs. 11-14). It should be noted here that the combined

13 influence of joint climate indices on flood-affected and flood-destroyed crop areas is

14 uneven in the spatial distribution without clear and apparently confirmative spatial

15 patterns. However, coherency in the combined influence of climate indices on

16 flood-affected and flood-destroyed crop areas can help predict flood-affected and

17 flood-destroyed crop areas based on the occurrence of climate indices in different 18 parts of China.

\section{Conclusions}

Temporal and spatial modes of flood-destroyed and flood-affected crop areas of 26 provinces of China are obtained, based on the REOF-based decomposition.

23 Influences of climate indices, ENSO, NAO, IOD, PDO and AMO, on flood-affected and flood-destroyed crop areas are analyzed. The following conclusions are drawn 
from this study:

2 (1) Warm IOD and PDO events of the previous year tend to cause an increase in

3 flood-affected crop areas of the subsequent year in northwest China and warm PDO

4 phases tend to trigger an increase in flood-affected crop areas of the same year in

5 northwest China. However, warm ENSO events have the potential to cause a

6 decrease in flood-affected crop areas of its next year in southwest China.

7 Flood-affected crop areas in northeast and south China tend to increase under the

8 influence of warm PDO of the previous years. Furthermore, warm NAO episodes

9 usually cause an increase in flood-affected crop areas of the subsequent years in northeast and east China. Similar spatial and temporal patterns can be found for the

11 influence of climate indices on flood-destroyed crop areas when compared to

flood-affected crop areas. Flood-destroyed crop areas in northeast and south China tend to increase due to the warm PDO events of the previous years, and flood-destroyed crop areas in central China have the potential to increase due to the occurrence of warm PDO events of the same and previous years and also cold ENSO events of the previous years. Notably, flood-destroyed and flood-affected crop areas in the coastal provinces of China are both influenced by multiple climate indices.

(2) Changes in flood-affected and flood-destroyed crop areas at different time scales are subject to different degrees of correlation with climate indices. Remarkably, climate indices which have significant correlation relations with flood-affected and flood-destroyed crop areas usually exhibit temporally enhancing and persistent correlations with flood-destroyed and flood-affected crop areas. This finding is 
meaningful for the prediction of flood-destroyed and flood-affected crop areas across

2 China. Amongst five climate indices considered in this study, ENSO regimes usually

3 have significant correlations with flood-affected and flood-destroyed crop areas and

4 these relations tend to be enhancing in recent years with a substantial degree of

5 correlation. This suggests that ENSO can be taken as an ideal predictor for

6 flood-affected and flood-destroyed crop areas in China.

7 (3) Influences of individual climate indices and combined influences of groups of

8 climate indices on flood-affected and flood-destroyed crop areas are similar in both

9 space and time. Cold NAO and cold PDO regimes can likely trigger a decrease of

10 agricultural floods in most provinces of China; on the contrary, cold ENSO regimes

11 and cold IOD events can probably cause an increase of agricultural flood hazards.

12 Furthermore, cold AMO events can lead to an increase in agricultural flood hazards

13 in northeast China and the coastal regions of southeast China. This result should

14 arouse considerable concern for the mitigation of agricultural flood hazards and also

15 planning and management of agricultural activities.

(4) Combined influences of climate indices on flood-affected and flood-destroyed crop areas across China are not subject to confirmative spatiotemporal patterns. Significant influences of PDO and NAO events on agricultural floods are identified mainly in the coastal provinces of southeast China and in central China. Cold PDO and cold IOD events influence flood-affected and flood-destroyed crop areas in central and south central China. However, cold AMO and cold NAO tend to influence flood-affected and flood-destroyed crop areas in coastal provinces of east 
1 China. Results of this study provide a picture for the prediction of flood-affected and

2 flood-destroyed crop areas under the influence of different climate indices,

3 particularly the five climate indices considered in this study.

4

5 Acknowledgments: This work is financially supported by the National Science

6 Foundation for Distinguished Young Scholars of China (Grant No.: 51425903), the

7 Xinjiang Science and Technology Planning Project (Grant No.: 201331104), the

8 Natural Foundation of Anhui Province (Grant No.: 1508085MD65), Project supported by

9 the Funds for International Cooperation and Exchange of the National Natural Science Foundation of China (Grant No. 51210013), and is fully supported by a grant from the Research Grants Council of the Hong Kong Special Administrative Region, China (Project No. CUHK441313). Detailed information such as data can be obtained by writing to the corresponding author at zhangq68@mail.sysu.edu.cn. Our cordial gratitude should be extended to the editor, Prof. Sierd Cloetingh, and two anonymous reviewers for their professional comments and suggestions which are greatly helpful for further improvement of the quality of the manuscript.

\section{References:}

Alan, D.Z., S. Justin, P.M. Edwin, N. Bart, F.W. Eric, and P.L. Dennis, 2003. Detection of intensification in global- and continental-scale hydrological cycles: Temporal scale of evaluation. Journal of Climate 16, 535-547. 
1 Allen, M., Ingram, W.J., 2002. Constraints on future changes in climate and the hydrologic cycle. Nature 419, 224-232.

Bouwer, L.M., Vermaat, J.E., Aerts, J.C.J.H., 2008. Regional sensitivities of mean and peak river discharge to climate variability in Europe. Journal of Geophysical Research 113, D19103.

Chau, V.N., J. Holland, S. Cassells, M. Tuohy, 2013. Using GIS to map impacts upon agriculture from extreme floods in Vietnam. Applied Geography 41, 65-74.

Das, T., E.P. Maurer, D.W. Pierce, M.D. Dettinger, D.R. Cayan, 2013. Increases in flood magnitudes in California under warming climates. Journal of Hydrology 501, 101-110.

Delgado, J.M., Merz, B., Apel, H., 2012. A climate-flood link for the lower Mekong River. Hydrology and Earth System Sciences 16, 1533-1541.

Dore, H.I.M., 2005. Climate change and changes in global precipitation patterns: What do we know? Environmental International 31, 1167-1181.

Easterling, D.R., Meehl, G.A., Parmesan, C., Changnon, S.A., Karl, T.R., Mearns, L.O., 2000. Climate extremes: observations, modeling, and impacts. Science 289, 2068-2074.

Hannachi, A., Jolliffe, I.T., Stephenson, D.B., 2007. Empirical orthogonal functions and related techniques in atmospheric science: A review. International Journal of Climatology 27(9), 1119-1152.

Li, J., Q. Zhang, Chen, Y.D., V.P. Singh, 2015. Future joint probability behaviors of precipitation extremes across China: spatiotemporal patterns and implications for 
MacDonald, M.G., 2010. Water, climate change, and sustainability in the southwest. PNAS 107(50), 21256-21262.

Mirza, M.M.Q., 2002. Global warming and changes in the probability of occurrence of floods in Bangladesh and implications. Global Environmental Change 12, 127-138.

Moore, G.W.K., Renfrew, I.A., Pickart, R.S., 2013. Multidecadal Mobility of the North Atlantic Oscillation. Journal of Climate 26(8), 2453-2466.

Ouyang, R., W. Lin, G. Fu, C. Liu, L. Hu, and H. Wang, 2014. Linkages between 

476, 154-168.

Reynard, N.S., Prudhomme, C., Crooks, S.M., 2001. The flood characteristics of large UK rivers: potential effects of changing climate and land use. Climate Change 48, 343-359.

Schmidhuber, J. and Tubiello, N.F., 2007. Global food security under climate change. PNAS 104(50), 19703-19708.

Villarini, G., Smith., J.A., Serinaldi, F., Ntelekos, A.A., Schwarz, U., 2012. Analyses of extreme flooding in Austria over the period 1951-2006. Int. J. Climatol. 32, 1178-1192.

Wang, Y., S. Li, D. Luo, 2009. Seasonal response of Asian monsoonal climate to the Atlantic Multidecadal Oscillation. Journal of Geophysical Research 114, D02112.

Xiao, M., Q. Zhang, V.P. Singh, 2015. Influences of ENSO, NAO, IOD and PDO on seasonal precipitation regimes in the Yangtze River basin, China. International Journal of Climatology DOI: 10.1002/joc.4228.

Xu, L., Q. Zhang, A.-L. Zhou, R. Huo, 2013. Assessment of flood catastrophe risk for grain production at the provincial scale in China based on the BMM method. Journal of Integrative Agriculture 12(12), 2310-2320.

Zaroug, M.A.H., Eltahir, E.A.B., Giorgi, F., 2014. Droughts and floods over the upper catchment of the Blue Nile and their connections to the timing of El Niño and La Niña events. Hydrology and Earth System Sciences 18, 1239-1249. 
Zhang, F., Chen, X., P. Vitousek, 2013. Chinese agriculture: An experiment for the world. Nature 497, 33-35.

Zhang, Q., V.P. Singh, J. Li, X. Chen, 2011. Analysis of the periods of maximum consecutive wet days in China. Journal of Geophysical Research 116, D23106, doi:10.1029/2011JD016088.

Zhang, Q., P. Sun, V.P. Singh, X. Chen, 2012. Spatial-temporal precipitation changes (1956-2000) and their implications for agriculture in China. Global and Planetary Change (82-83), 86-95.

Zhang, Q., J. Li, V.P. Singh, M. Xiao, 2013a. Spatio-temporal relations between temperature and precipitation regimes: Implications for temperature-induced changes in the hydrological cycle. Global and Planetary Change 111, 57-76.

Zhang, Q., J. Li, V.P. Singh, C.-Y. Xu, J. Deng, 2013b. Influence of ENSO on precipitation in the East River basin, south China. Journal of Geophysical Research 118, 2207-2219.

Zhang, Q., M. Xiao, V.P. Singh, Y.D. Chen, 2014. Max-stable based evaluation of impacts of climate indices on extreme precipitation processes across the Poyang Lake basin, China. Global and Planetary Change 122, 271-281.

Zhang, Q., P. Sun, J. Li, V.P. Singh, J. Liu, 2015. Spatiotemporal properties of droughts and related impacts on agriculture in Xinjiang, China. International Journal of Climatology DOI: 10.1002/joc.4052. 


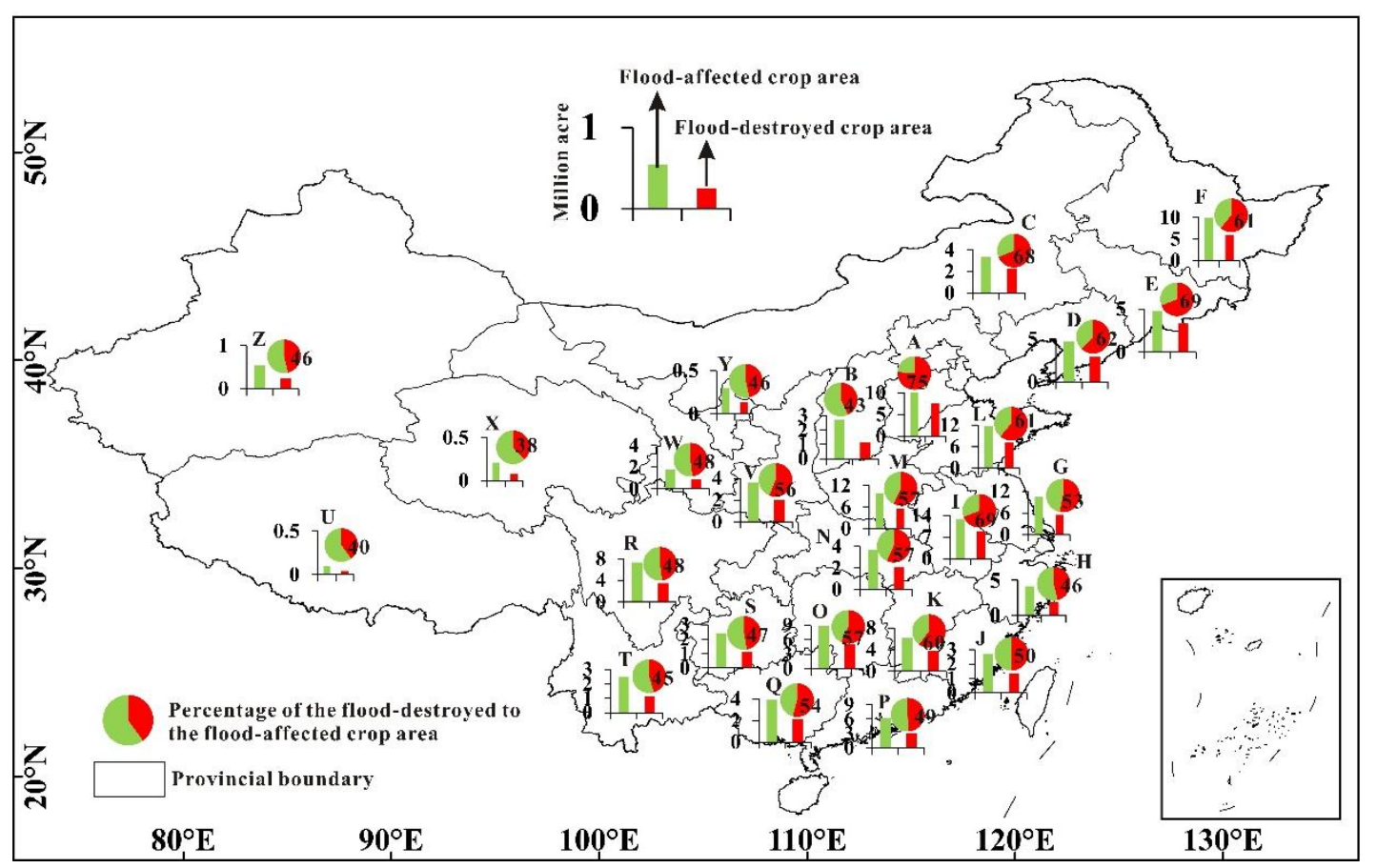

Fig. 1 Long-term average flood-affected, flood-destroyed crop areas and the percentage of flood-destroyed crop areas to flood-affected crop areas across 26 provinces of China. The provinces marked by capital letter are: A: Hebei; B: Shanxi; C: Inner Mongolia; D: Liaoning; E: Jilin; F: Heilongjiang; G: Jiangsu; H: Zhejiang; I: Anhui; J: Fujian; K: Jiangxi; L: Shandong; M: Henan; N: Hubei; O: Hunan; P: Guangdong; Q: Guangxi; R: Sichuan; S: Guizhou; T: Yunnan; U: Tibet; V: Shannxi; W: Gansu; X: Qinghai; Y: Ningxia; and Z: Xinjiang. 


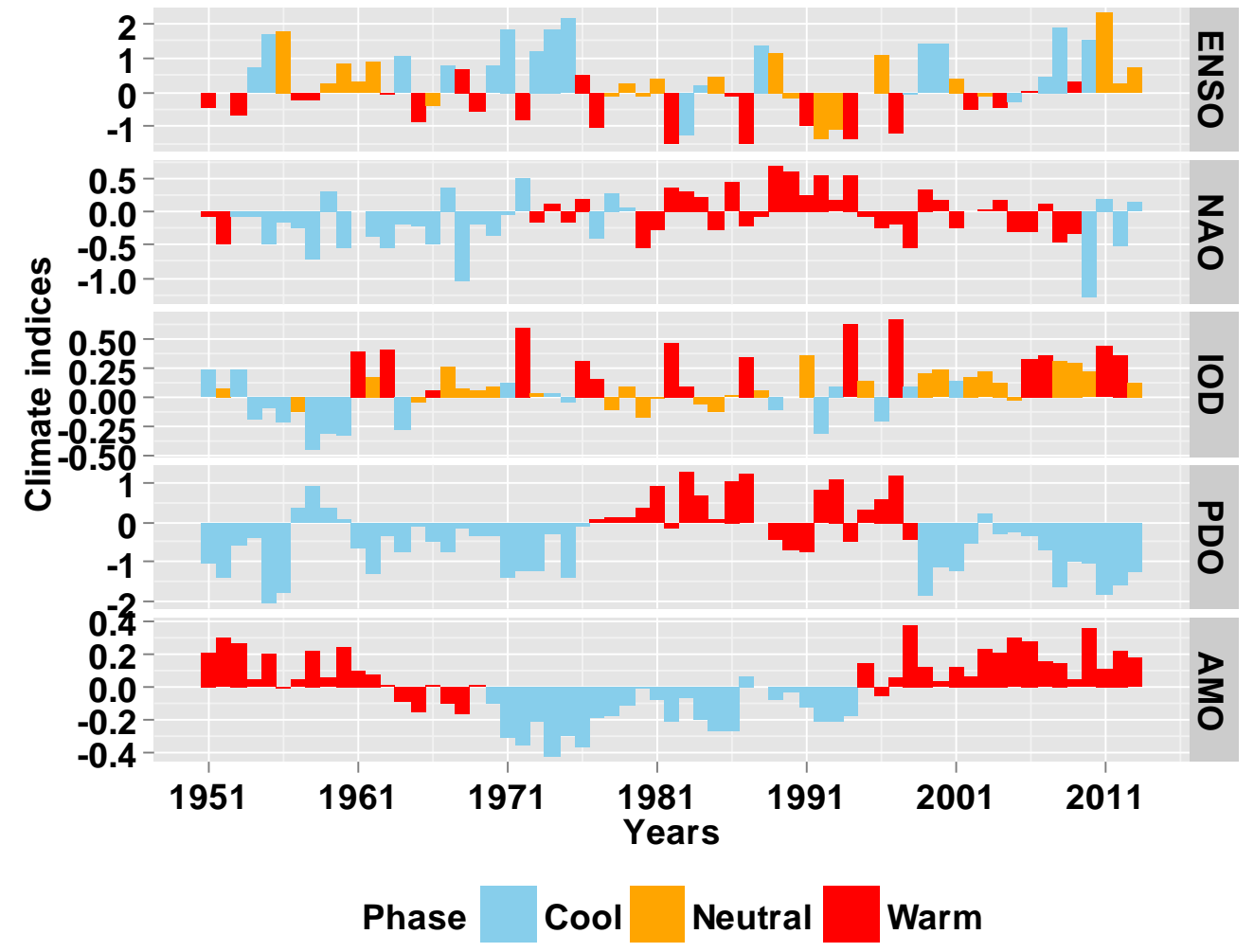

Fig. 2 Temporal variations of cold and warm episodes of the ENSO, NAO, IOD, PDO and AMO events during 1951-2013 


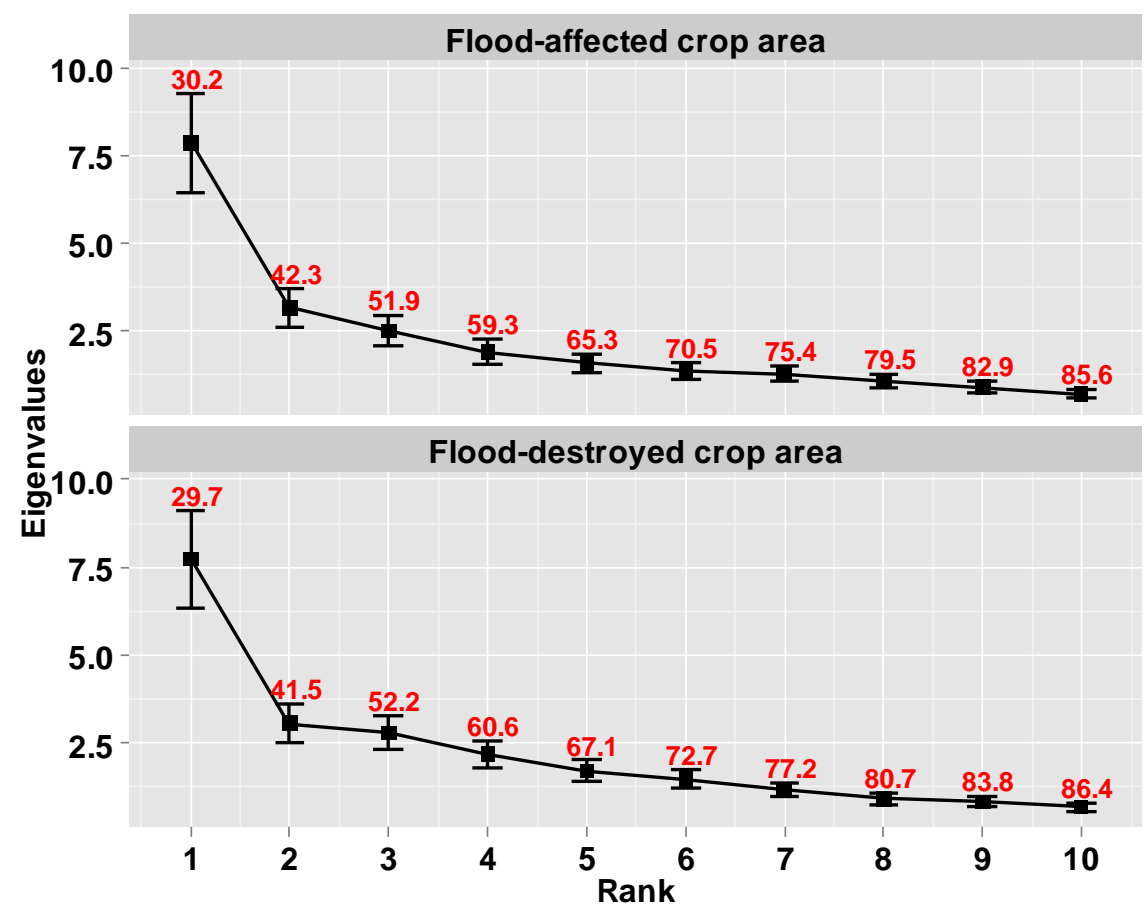

Fig. 3 REOF eigenvalues and accumulative explained variance of the anomaly series of the flood-affected and flood-destroyed crop areas across China. The numbers lining along the curves denote the accumulated explained variance. The bars along with the curves denote the upper and lower limits of the $95 \%$ confidence level. 


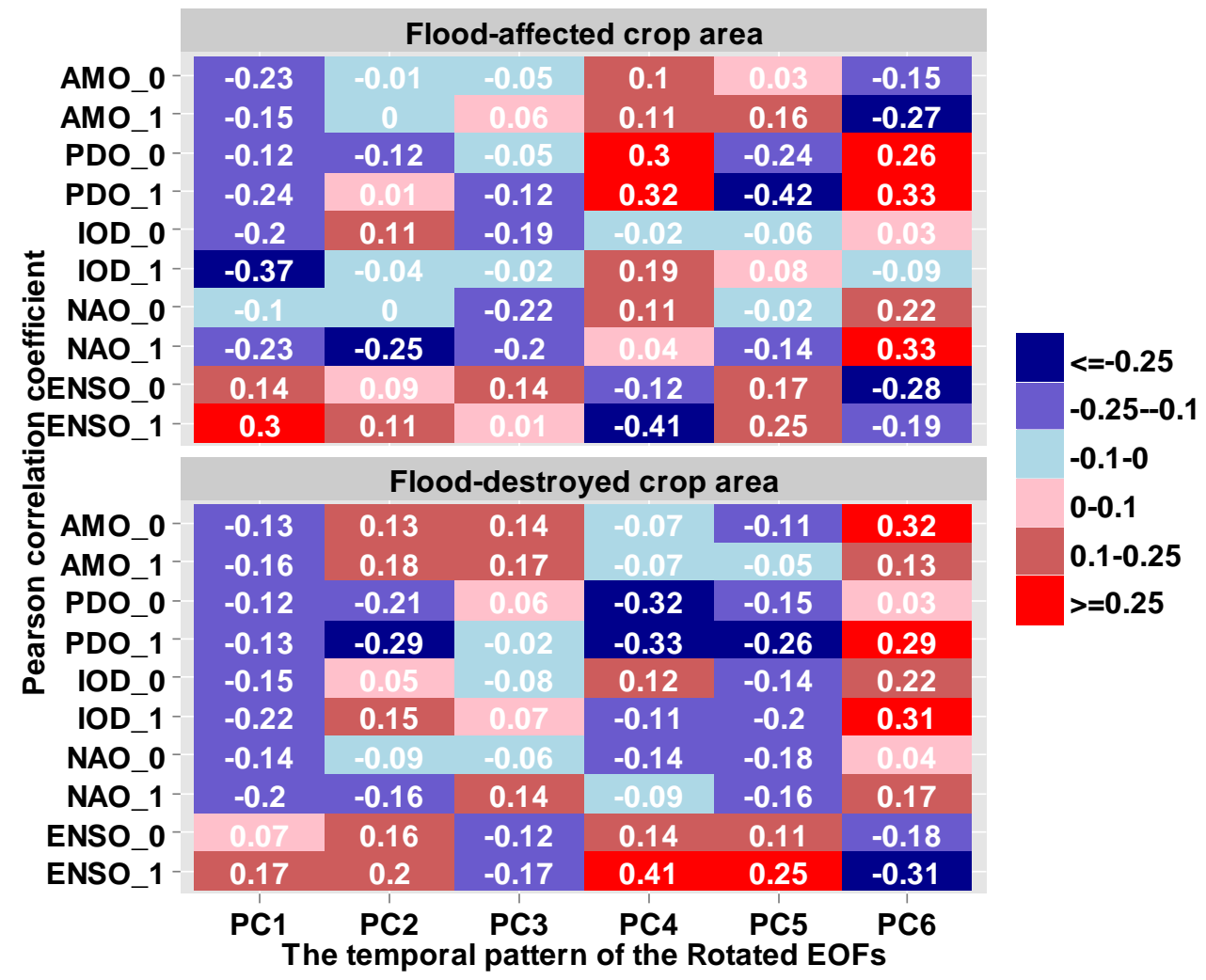

Fig. 4 Pearson correlation coefficients between REOFs-based temporal modes and climate indices. The 0 and 1 behind the short line after the climate indices denotes 0 and 1-year time lag before the flood-affected and flood-destroyed crop area series. The correlation coefficient being larger than or equaling 0.25 is significant at $95 \%$ confidence level. PC1 denotes the first principle component and the same denotation for PC2, PC3 and so on. 


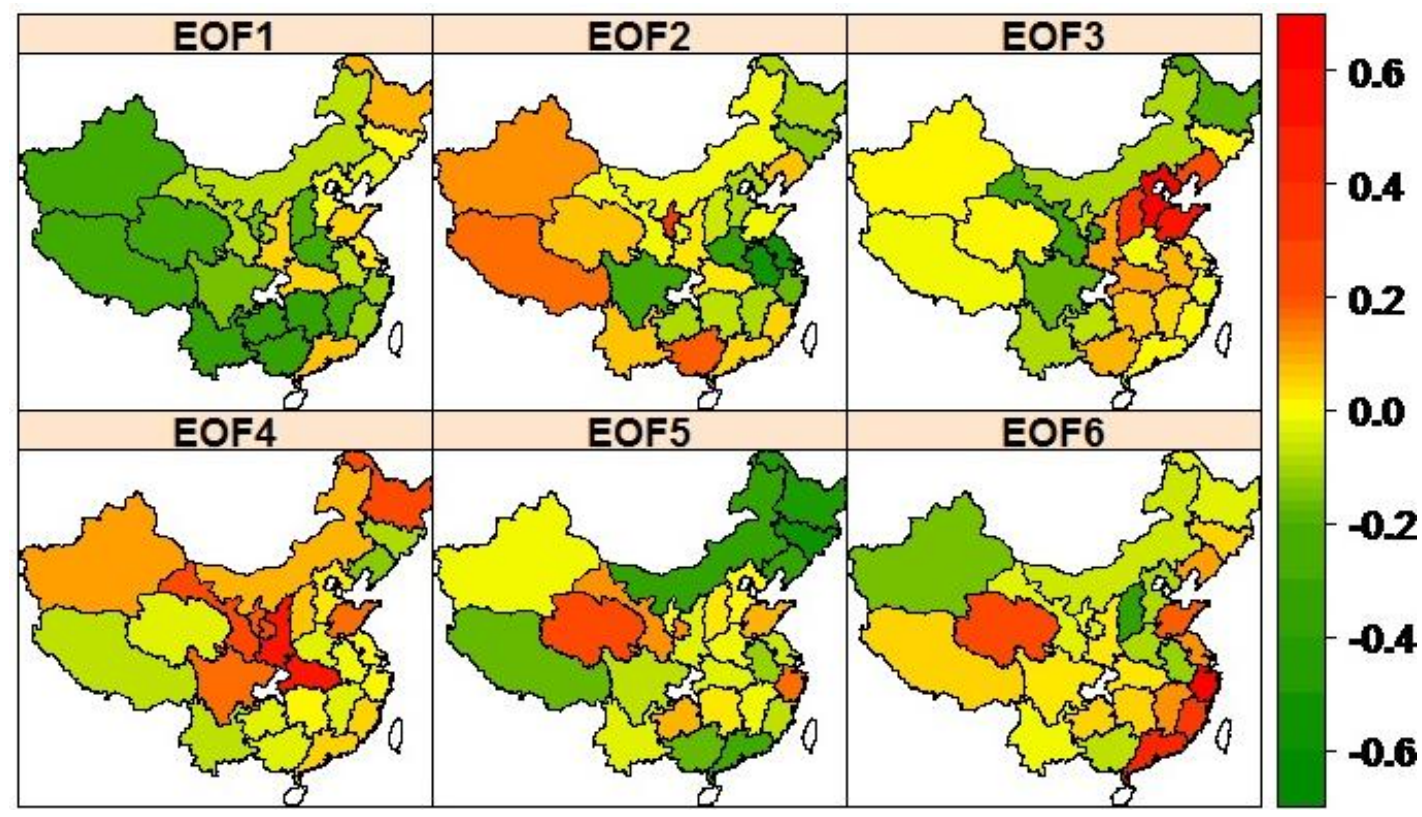

Fig. 5 REOFs-based spatial patterns of flood-affected crop areas across China 


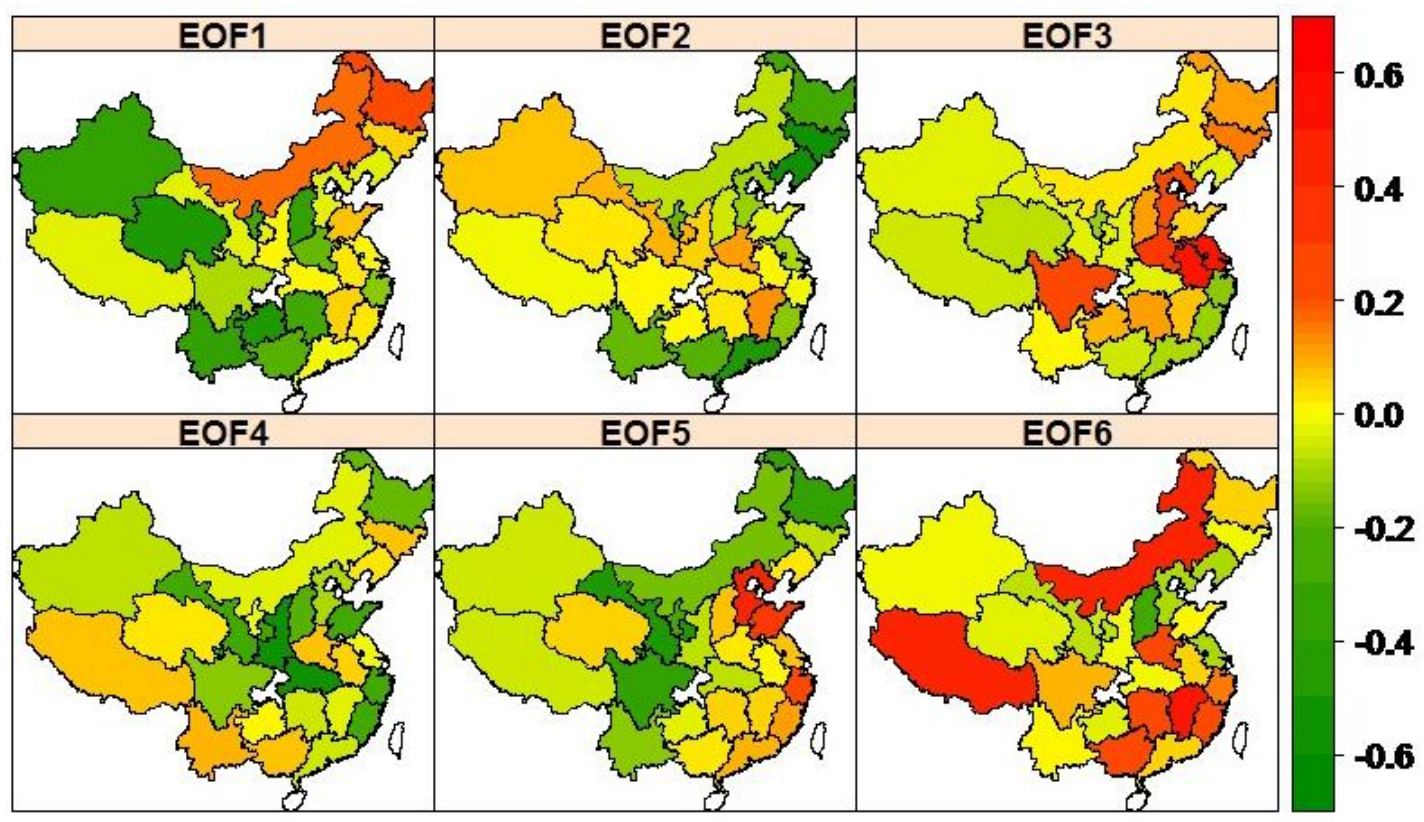

Fig. 6 REOFs-based spatial patterns of flood-destroyed crop areas across China 


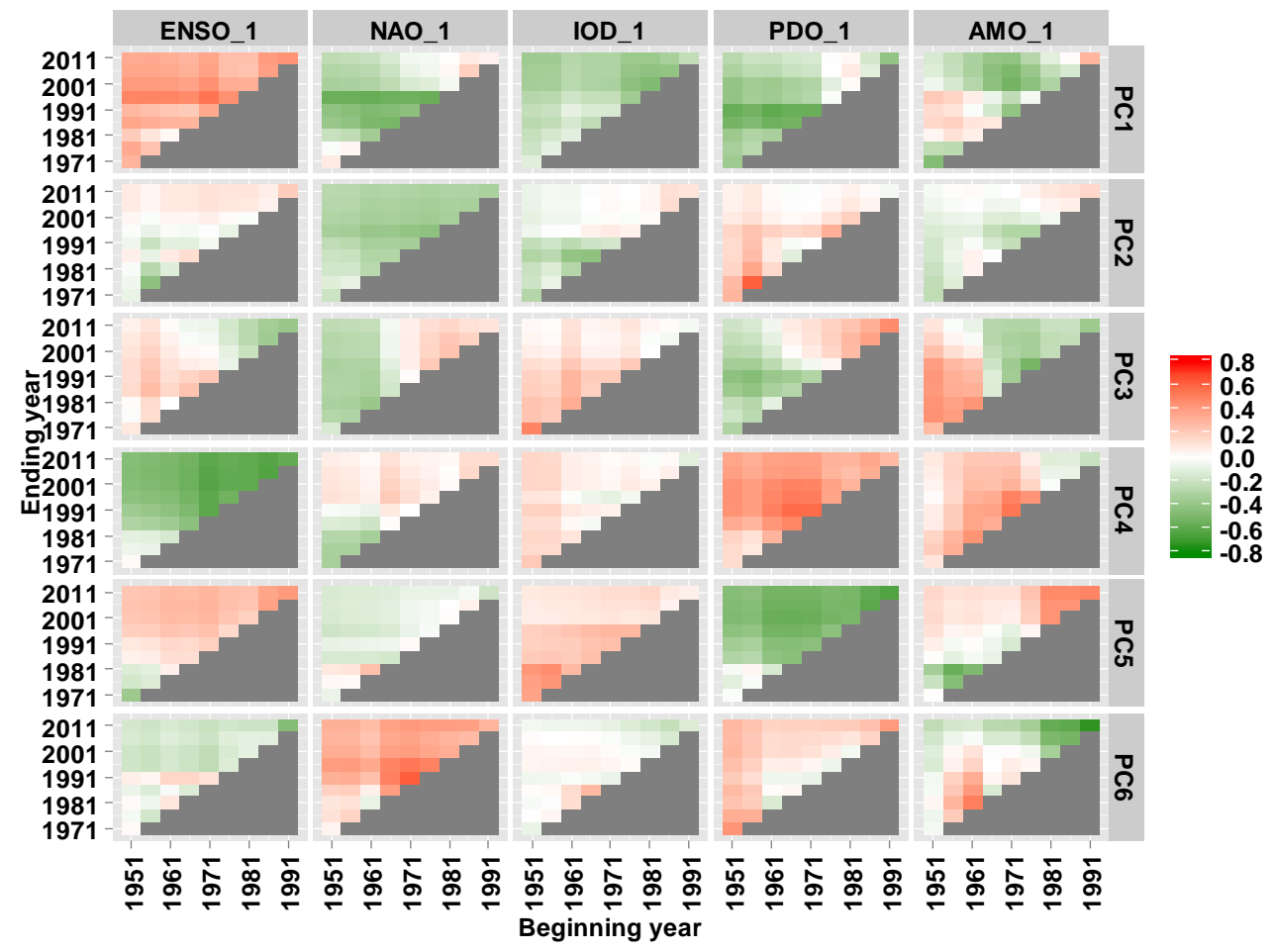

Fig. 7 Correlations between REOFs-based temporal modes of flood-affected crop areas and climate indices with one year ahead across China 


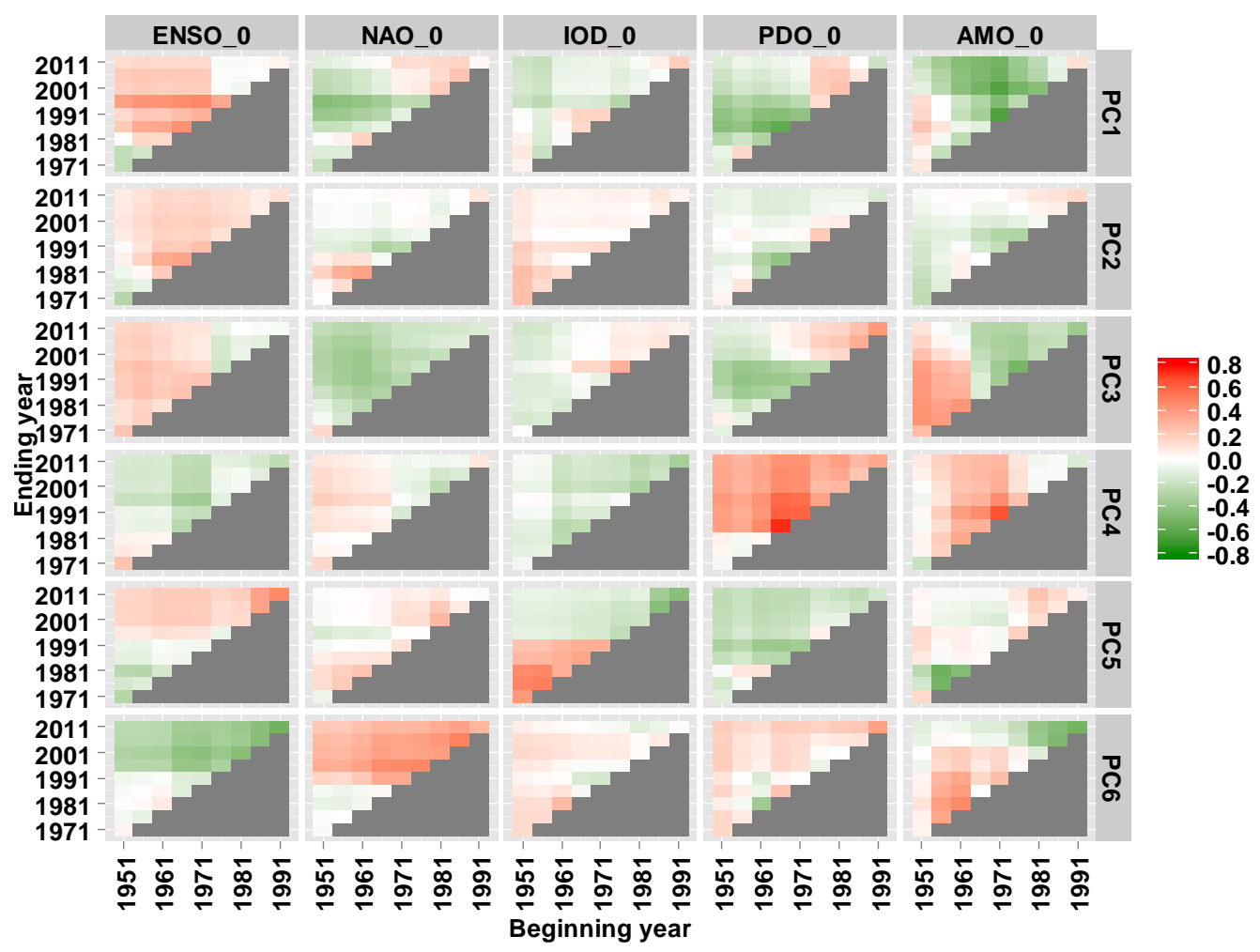

Fig. 8 Correlations between REOFs-based temporal modes of flood-affected crop areas and climate indices of the same year across China 


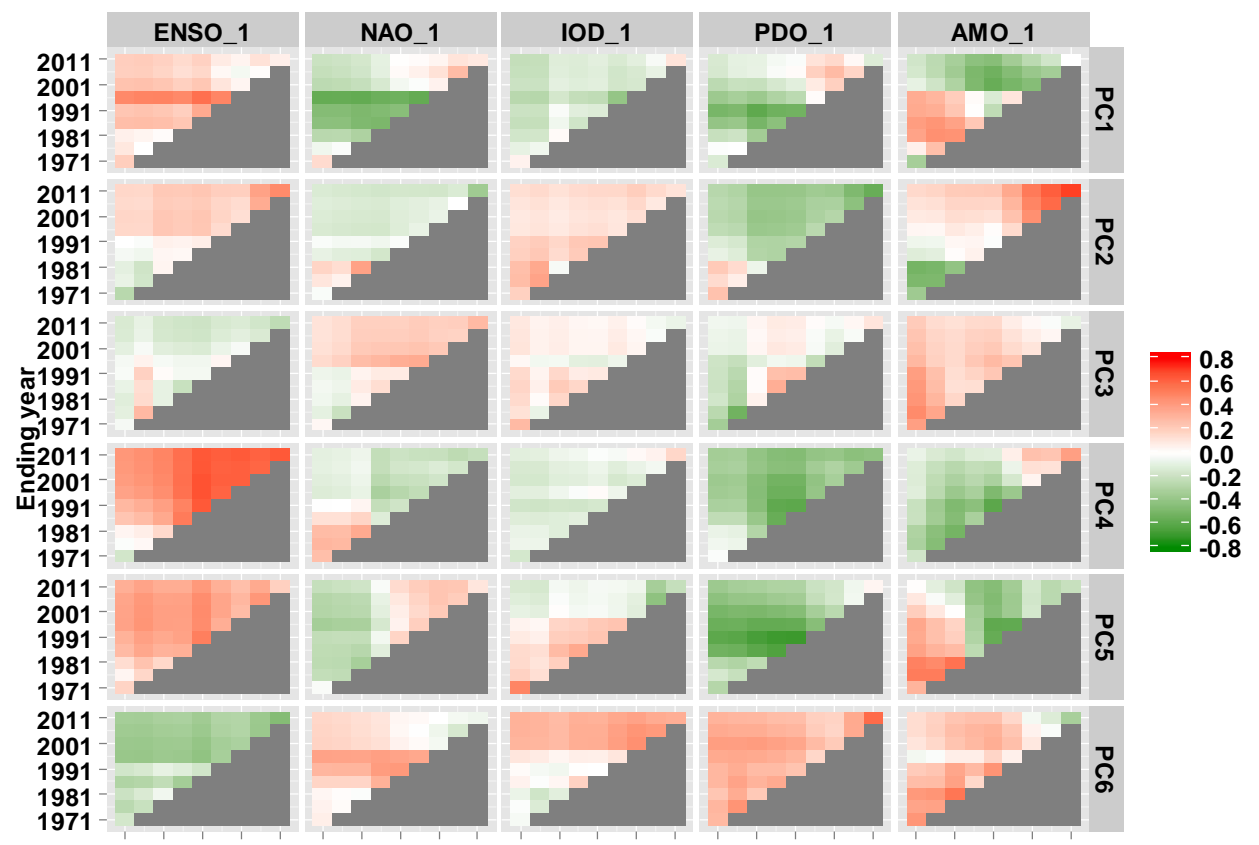

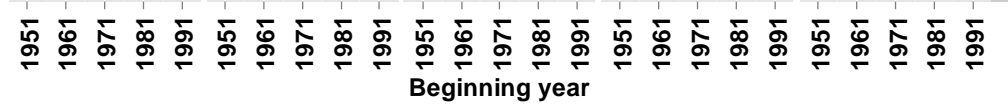

Fig. 9 Correlations between REOFs-based temporal modes of flood-destroyed crop areas and climate indices with one year ahead across China 


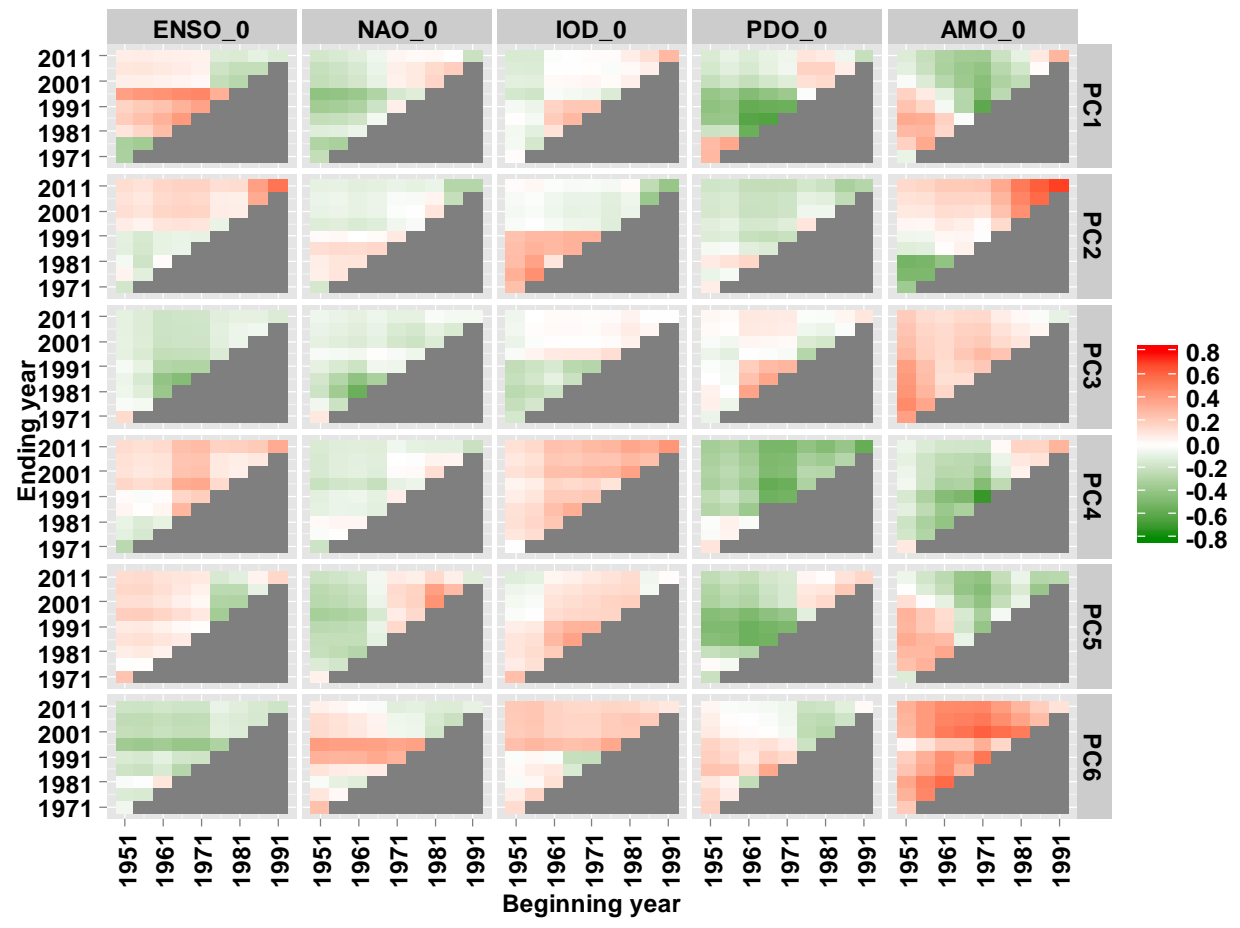

Fig. 10 Correlations between REOFs-based temporal modes of flood-destroyed crop areas and climate indices of the same year across China 

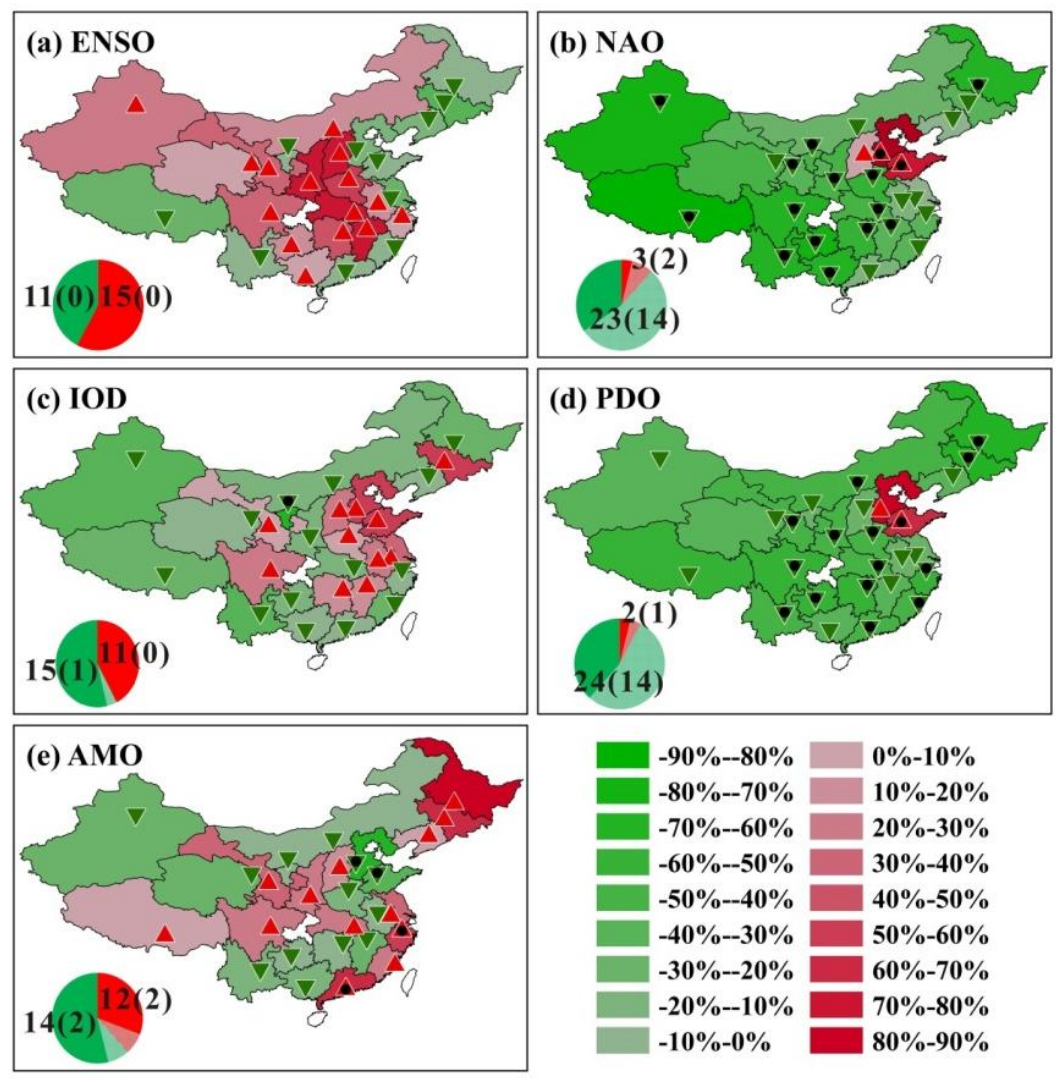

\begin{tabular}{|l|l}
$-\mathbf{9 0} \%--80 \%$ & $\mathbf{0} \%-\mathbf{1 0} \%$
\end{tabular}

\begin{tabular}{l}
$-80 \%--70 \%$ \\
\hline
\end{tabular}

\begin{tabular}{l}
$-70 \%--60 \%$ \\
\hline
\end{tabular}

$-60 \%--50 \% \quad 30 \%-40 \%$

$-50 \%--40 \% \quad 40 \%-50 \%$

$-\mathbf{4 0} \%--\mathbf{3 0} \% \quad \mathbf{5 0} \%-\mathbf{6 0} \%$

$\begin{array}{ll}-40 \%--30 \% & -50 \%-70 \% \\ -30 \% & 60 \%-70 \%\end{array}$

$-\mathbf{2 0} \%--10 \% \square \mathbf{7 0} \%-\mathbf{8 0} \%$

$-10 \%-0 \% \square 80 \%-90 \%$

Significant increasing Increasing

Significant decreasing $\nabla$ Decreasing

Fig. 11 Percentage of flood-affected crop areas during the cold episodes to those during warm episodes, i.e. (flood-affected crop areas during cold episodesflood-affected crop areas during warm episodes)/flood-affected crop areas during warm episodes. The significance level of the student $t$ test is 0.05 . The filled triangles with black points denote significant trends. 

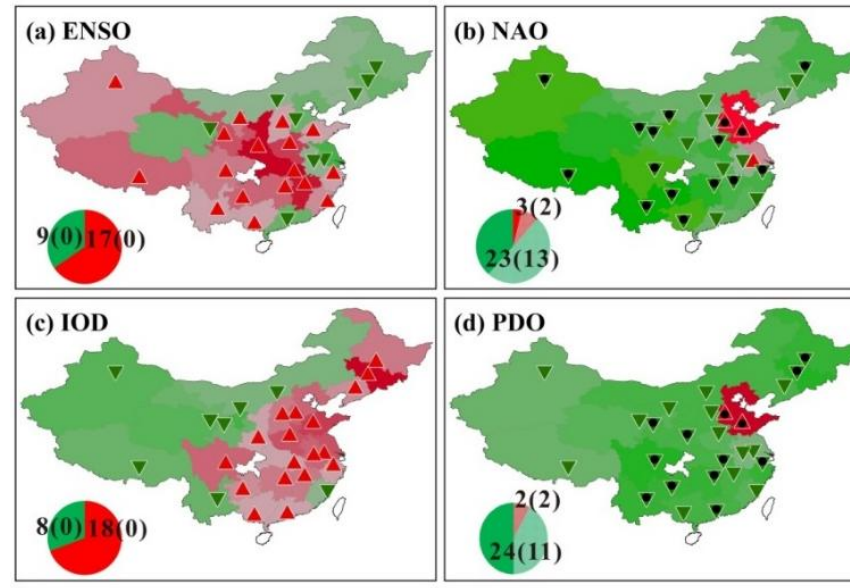

(d) PDO

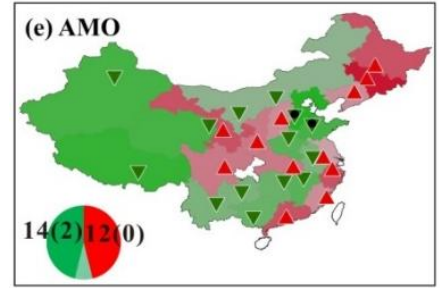

$-\mathbf{9 0} \%-\mathbf{- 8 0} \% \quad 0 \%-10 \%$

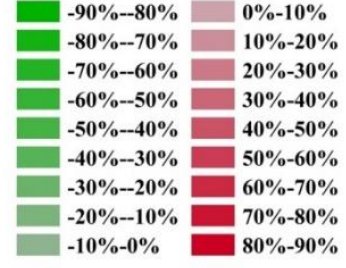

Aignificant increasing $\Delta$ Increasing $\nabla$ Significant decreasing $\nabla$ Decreasing

Fig. 12 Percentage of the flood-destroyed crop areas during cold episodes to those during warm episodes, i.e. (flood-destroyed crop areas during cold episodes-flood-destroyed crop areas during warm episodes)/flood-destroyed crop areas during warm episodes. The significance level of the student $t$ test is 0.05 . The filled triangles with black points denote significant trends. 


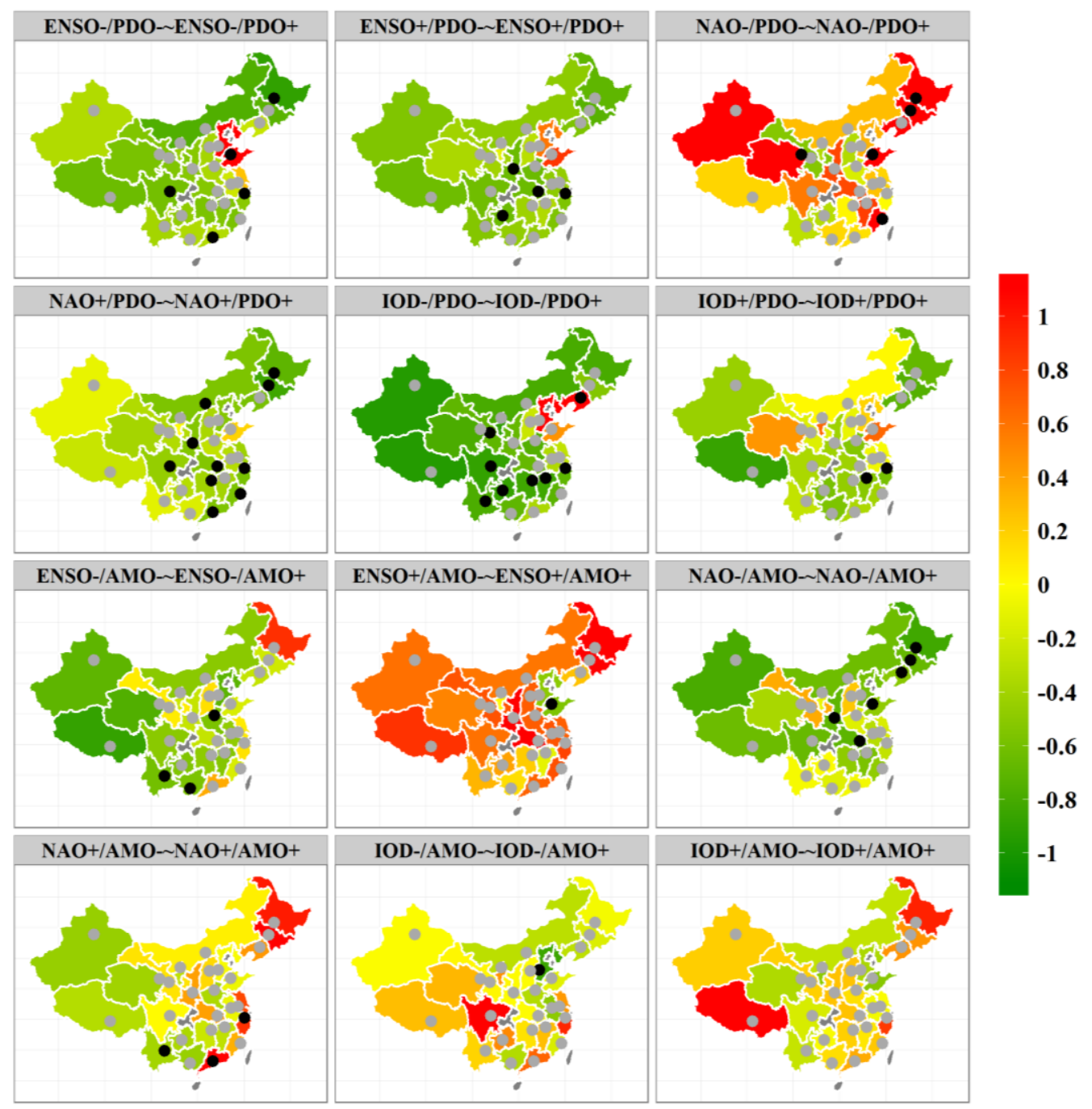

Fig. 13 Changes in the flood-affected crop areas under the combined influence of ENSO, NAO, IOD and PDO, AMO across China. Regions with black points indicate significant changes, and gray points not significant changes. 


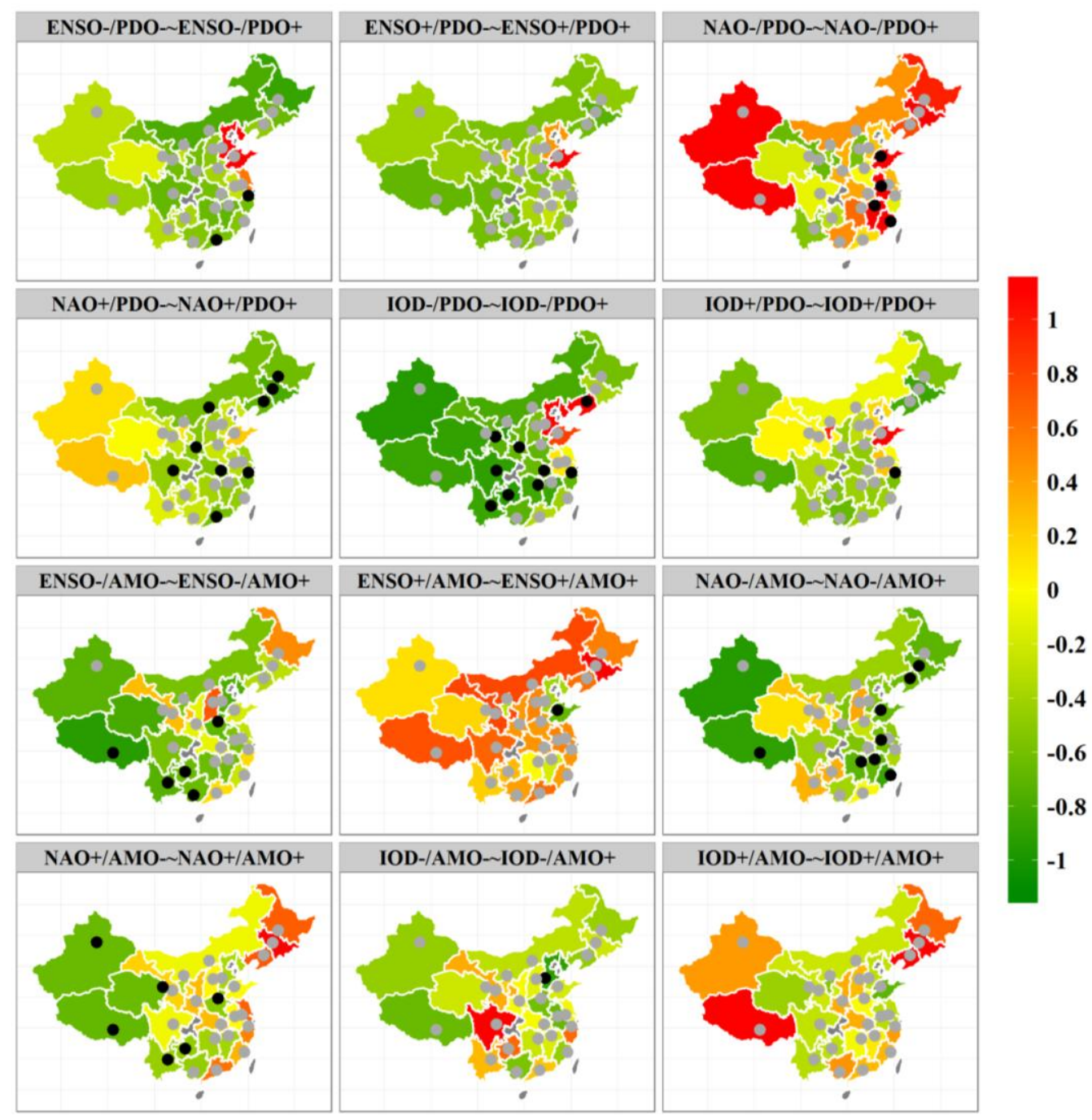

0.8
0.6
0.4
0.2

o

$-0.2$

Fig. 14 Changes in flood-destroyed crop areas under the combined influence of ENSO, NAO, IOD and PDO, AMO across China. Regions with black points indicate significant changes, and gray points not significant changes. 